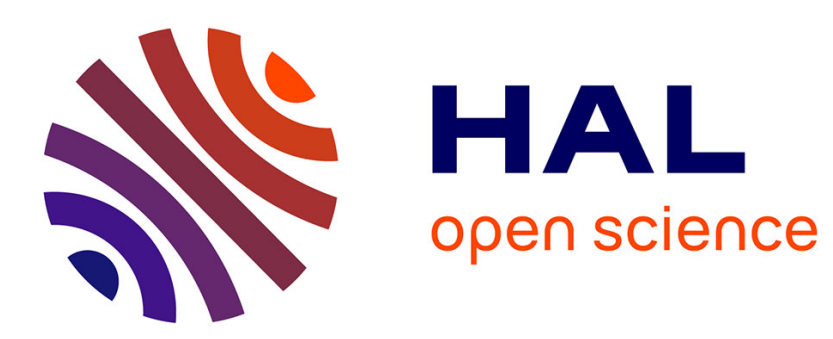

\title{
WHY BUSINESS SCHOOLS DO SO MUCH RESEARCH: A SIGNALING EXPLANATION
}

Damien Besancenot, Joao Faria, Radu Vranceanu

\section{To cite this version:}

Damien Besancenot, Joao Faria, Radu Vranceanu. WHY BUSINESS SCHOOLS DO SO MUCH RESEARCH: A SIGNALING EXPLANATION. 2008. halshs-00241259

\section{HAL Id: halshs-00241259 \\ https://shs.hal.science/halshs-00241259}

Preprint submitted on 6 Feb 2008

HAL is a multi-disciplinary open access archive for the deposit and dissemination of scientific research documents, whether they are published or not. The documents may come from teaching and research institutions in France or abroad, or from public or private research centers.
L'archive ouverte pluridisciplinaire HAL, est destinée au dépôt et à la diffusion de documents scientifiques de niveau recherche, publiés ou non, émanant des établissements d'enseignement et de recherche français ou étrangers, des laboratoires publics ou privés. 
WHY BUSINESS SCHOOLS DO SO MUCH RESEARCH: A SIGNALING EXPLANATION

\author{
Damien Besancenot; Joao Ricardo Fariał, Radu Vranceanu ${ }^{\ddagger}$
}

\begin{abstract}
Criticism is mounting on business schools for their excessive focus on research and for neglecting teaching. We show that if students have imperfect information about a school's overall capabilities and if business schools differ in their research productivity, the least productive schools may do as much research as the top-tier ones only to manipulate students' expectations. In turn, the most productive schools might resort to excess research in order to signal their type in the eyes of future students. This signaling equilibrium is characterized by a relative neglect of teaching by the top-tier schools. Such a situation is socially inefficient as compared to the perfect information case.
\end{abstract}

Keywords: Business Schools, Research management, Research policy, Research vs. teaching, Signalling, Imperfect information.

JEL Classification : I23; D82

Document de travail CEPN 2008-005

*University Paris 13 and CEPN, Paris, France. E-mail: besancenot.damien@univ-paris13.fr

${ }^{\dagger}$ Nottingham Business School, Burton St., Nottingham NG1 4BU, UK. E-mail: joao.faria@ntu.ac.uk

‡ESSEC Business School, PB 50150, 95021 Cergy, France. E-mail: vranceanu@essec.fr. 


\section{Introduction}

The ongoing development of the service sector in the Western economies and the increased competition between firms in a globalized world brought about a substantial demand for high quality managerial skills. This transformation helped Business Schools [B-Schools, thereafter] to become important players in the education sector. While in the 1950 s their main purpose was to provide basic, professionally oriented education, these days scholarship and research become essential dimensions of their mission such as understood by society and by themselves. Since a school's reputation is connected to its research performance (Armstrong, 1995; Becker et al., 2003), in an ever more globalized environment B-Schools have no other choice than to compete on this dimension too (Kwok and Arpan, 2002).

Yet the growing enthusiasm of B-Schools for theoretical advances has been subject to criticism in the last few years. A recent report of the AACSB summarizes well the widespread popular grief: "business schools have recently been criticized for placing too much emphasis on research relative to teaching, and for producing research that is too narrow, irrelevant and impractical" (AACSB, 2007, p.6). ${ }^{1} \quad$ The criticism sounds louder with respect to the top institutions. For instance, Bennis and O'Toole (2005, p.98) claim that: "many leading B-Schools have quietly adopted an inappropriate - and ultimately self defeating - model of academic excellence. Instead of measuring themselves in terms of the competence of their graduates, or by how well their faculty understand important drivers of business performance, they measure themselves almost solely by the rigor of their scientific research".

Why schools would engage in a race for publications that brings only a limited direct value to students and managers? Some authors have indicated that excess research can be a Nash equilibrium strategy in a game where each Dean pushes his faculty to target the top-tier journals, although such a generalized strategy harms the quality of the top-tier journals and the returns from publishing (Besancenot and Vranceanu, 2007; Besancenot et al., 2008). Other explanations put forward some form of Deans' irrationality, who, being fascinated by rankings, would become

\footnotetext{
1 The report, which in general supports the business schools concern for developing new managerial theories, makes a strong case for enhancing their impact of research and education on various constituencies.
} 
unable to perceive what firms and students really need (e.g., Pfeffer and Fong, 2002; Bennis and O'Toole, 2005).

A simple signaling model ${ }^{2}$ may provide an alternative explanation for the abnormal investment in research by B-Schools. "Normality" will be defined in a very specific way, as the amount of research that would prevail in a perfect information set-up. If future students cannot assess the overall quality of a business school, some schools may implement excess research strategies only to signal their type. The model features two types of schools, which differ in their efficiency in the production of research. We refer to the highly efficient ones as $H$-schools, and to the less efficient ones as $L$-schools. A key assumption is that information is imperfect. More precisely, future students, who value both teaching quality and research, can observe only the latter. Indeed, in the Internet Era, the research performance of a given school is easy to grasp. Many bibliometric measures are available and media, researchers and administrations use them to provide yearly rankings and evaluations of various schools and departments. Schools themselves advertise loudly about their research credentials and achievements. ${ }^{3}$ To the contrary, the quality of an education programme is much more difficult to measure. True, the formal aspect (textbooks, cases, teaching material) can be observed, but less so the quality of the curriculum, i.e., whether it is really adapted to the new challenges for tomorrow managers, whether it takes into account the most relevant theories, whether it uses the most efficient teaching methods. As mentioned by Demski and Zymmerman (2000, p. 343), "faculties often have better information about what students will find useful than the students themselves, or even recruiters". Paul and Rubin (1984, p. 143) state that "in most disciplines, students are, by definition, incapable of judging the 'state of the art' or of determining the 'usefulness' of the material presented in class."

In this context, an equilibrium is defined as a situation where schools implement their optimal research strategies and students' beliefs are correct. We show that in a static framework, which takes as given the distribution of schools, the game presents several equilibria, most of them characterized by an excessive amount of research as compared to the perfect information case.

\footnotetext{
2 See for the basic framework Spence (1973, 2002) and Vickers (1986).

${ }^{3}$ Becker et al. (2003) found empirical evidence that students are attracted to schools by faculty research.
} 
Yet in a long run perspective, schools can modify their faculty profile. It seems reasonable to assume that the more productive scholars can get a better wage, given that they are more productive and that they probably have better outside opportunities (Faria, 2001; Coupé, 2004; Besancenot and Vranceanu, 2007). We will show that in this model, $L$-schools have little incentive to spend more in order to become $H$-schools, while the research oriented schools can have an incentive to become $L$-schools. Hence, in the long run the frequency of $H$-schools may well decline and the range of feasible equilibria gets narrower. If there is a large productivity gap between the two types of schools, in the long run all $H$-schools produce an excessive amount research and neglect teaching quality. If the productivity gap is narrow, in the long run $H$-schools will all choose to become $L$-schools, probably a much worse situation.

The paper is organized as follows. The next section introduces the basic assumptions and presents the benchmark perfect information case. The equilibria of the game are analyzed in section 3 , first in the large productivity gap and then in the small productivity gap case. The last section presents the conclusion.

\section{Main assumptions}

We assume that, in the short run, there are barriers to entry into the education business. Thus, the number of B-Schools is predetermined and will be normalized to one. The number of students that a school can recruit is given, and is equal across schools. All schools deliver an MBA; the curricula contains a fixed number of hours. Schools dispose of a fixed endowment in faculty work hours, $l$. Faculty members can used their working time either to do research $l_{R}$ or to improve the teaching quality $l_{T}$. The teaching quality depends on the hours spent by the faculty on pedagogical innovation and program development, $l_{T}$. The measure of quality in teaching is a continuous variable $T$. In the simplest framework, getting one teaching quality unit requires $a_{T}$ hours of work, i.e. $a_{T} T=l_{T}$.

When it comes to research, let $R$ be the amount of research produced by a school. ${ }^{4}$ The

\footnotetext{
4 There is no need to be very specific about how this measure is obtained; in general research is assessed by the contribution of the school to the intellectual debate, which may take the form of papers, books and other publications, interviews, etc.
} 
production of research is also assumed to be a linear function of the time devoted to this activity: $a_{R} R=l_{R}$, with $a_{R}$ a fixed production coefficient representing the number of hours needed to produce one research unit. We assume that scholars differ in their research productivity. Lety $a_{R}^{\tau}$ denote the number of hours needed to produce one research unit by a type $\tau$ scholar. There are two types of scholars, $H$ and $L$, with $a_{R}^{H}<a_{R}^{L}$, the $H$-scholar is more productive (i.e., needs less time to produce one research unit). To keep the model as simple as possible, we assume that some schools have recruited only $H$-type scholars and the other have recruited only $L$-type scholars. Hence, we have two types of schools either, the $H$-school, with a high research potential and the $L$-school, with a low research potential. The type $\tau$ is thus representative of both the school and its faculty. We denote by $q$ the frequency of $H$-schools.

Remark that in this paper schools differ only in the faculty research productivity, if all their writing hours were used for improving teaching quality, all schools would perform identically. To the contrary, if all their working time $l$ is used for research, the total volume of research is bigger for $H$-schools than for $L$-schools: $l / a_{R}^{H}>l / a_{R}^{L}$.

Under these assumptions, for a type $\tau$ school, the hour constraint (with equality, deans do their job) is:

$$
a_{R}^{\tau} R+a_{T} T=l, \text { with } \tau \in\{L, H\}
$$

To this constraint corresponds a "production frontier" made up of possible bundles $(T, R)$ to be obtained with the amount of hours $l$. To further simplify notation, we set $a_{T}=1$ and $l=1$. We represent in Figure 1 two production frontiers (one for each type of school $\tau$ ) in the plane $\{O T, O R\}$ as straight lines of slope $-\left(1 / a_{R}^{\tau}\right)$. When all resources are used to improve education quality, the latter is $l / a_{T}=1$; when all resources are used for research, $H$-schools produce $1 / a_{R}^{H}$ research units and $L$ schools produce $1 / a_{R}^{L}$ research units.

Notice that along the production frontier of a school $\tau$, a given level of research $R$ implies a level of education $T^{\tau}(R)$, with $\tau=H$ or $L$.

Students value both the quality of education and research (Armstrong, 1995; Becker et al., 2003; Demski and Zymmerman, 2000; AACSB, 2007). In a general form, we can represent their utility by a function $U(R, T)$, with $\frac{\partial U(,)}{\partial T}>0, \frac{\partial U(,)}{\partial R}>0$ and entailing convex indifference curves. ${ }^{5}$ 
Schools can charge tuition fees such that the expected surplus of the students is zero. So tuition fees are $\Phi(R)=E\left[U\left(R, T^{\tau}(R)\right)\right]$ with $\tau=H$ or $L$. Under these assumptions, in a perfect information set up, schools would simply choose the bundle $\left(R^{\tau}, T^{\tau}\right)$ that maximizes tuition fees given their hour constraint, such as indicated in Figure 1:

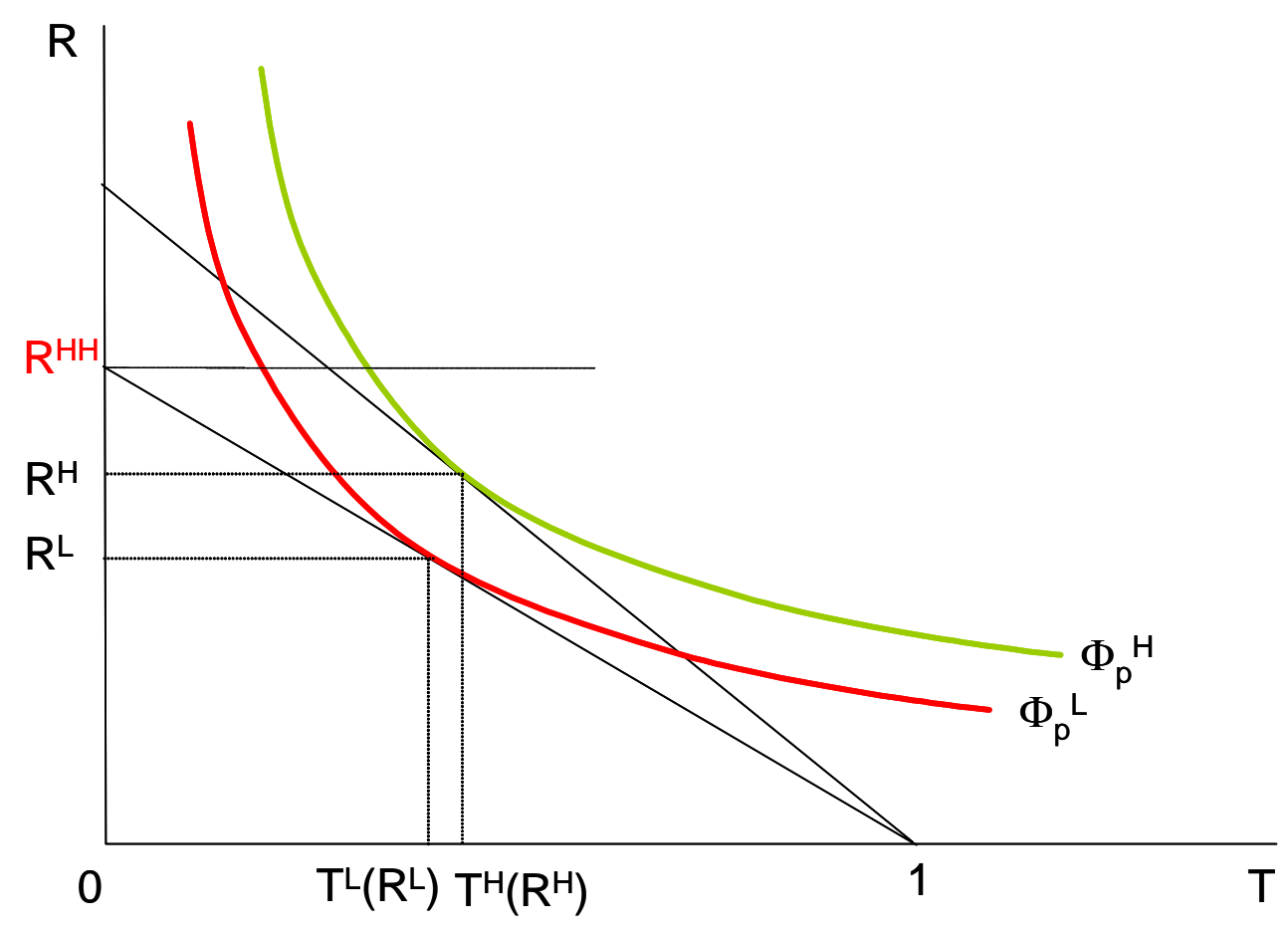

Figure 1: The Perfect Information Case

More precisely, the optimal amount of research under perfect information are $R^{L}$ (for the $L$ school) and $R^{H}$ (for the $H$-school). The connected teaching qualities are $T^{L}\left(R^{L}\right)$ and respectively $T^{H}\left(R^{H}\right)$. Tuition fees are equal to student's willingness-to-pay for the observed service levels, $\Phi_{p}^{L}=U\left(R^{L}, T^{L}\left(R^{L}\right)\right)$ for the $L$-school and $\Phi_{p}^{H}=U\left(R^{H}, T^{H}\left(R^{H}\right)\right)$ for the $H$-school, where the $p$ subscript indicates the perfect information case. In Figure 1, we represented a situation where $T^{L}\left(R^{L}\right)<T^{H}\left(R^{H}\right)$. This is not a necessary condition and our analysis also holds in the opposite case, $T^{L}\left(R^{L}\right)>T^{H}\left(R^{H}\right)$. However, this case, where teaching is a "normal" good and the income effect offsets the substitution effect seems to be the most realistic.

5 A specific utility function featuring these more general properties can be worked out if students care about their discounted flow of income. School's reputation or research should have a strong impact on the first period wage (with decreasing weights on next periods) and education, by enhancing student's productivity, has a substantial impact on lifetime wages. 
However, the assumption of perfect information - useful for introducing the basic notation - is not very realistic given that an education programme can be seen as a very complex commodity. So, in order to build our model on a logic of imperfect information, we need several additional assumptions. We will assume that research is an observable variable, that can be measured by standard indicators (quality adjusted number of publication, number of citations, etc.). Students can also assess the formal aspect of education (classes' sizes, teaching material, library facilities, etc.) however they have no means to assess whether the content is relevant, up-to-date, original, innovative, etc. In other words, the quality of teaching is private information to the school. Furthermore, students know the distribution of types of schools.

In an imperfect information set-up, the set of strategies is more sophisticated. A $L$-school may deliver its perfect information research level $R^{L}$; it can also play $R^{H}$, the perfect information research level of the $H$-school. A $H$-school can produce its perfect information research level $R^{H}$; if they want to make sure that $L$-schools do not imitate them, they should produce a so high amount of research that a $L$-school cannot deliver it (recall that $L$-schools have a lower research productivity). Let us denote by $R^{H H}$ this lowest level of research unattainable by a $L$-school (see Figure 1), $R^{H H}$ is the second research strategy available for a $H$-school. Notice that a $H$-school would never play $R^{L}$, because it has no interest to go for a $L$-school. ${ }^{6}$

For a research level $j \in\{L, H, H H\}$, a school's payoff is $\Phi\left(R^{j}\right)=E\left[U\left(R^{j}, T^{\tau}\left(R^{j}\right)\right)\right]$. Notice that research levels $R^{H H}$ and $R^{L}$ reveal perfectly a school's type. Thus $\Phi\left(R^{H H}\right)=U\left(R^{H H}, T^{H}\left(R^{H H}\right)\right)$ and $\Phi\left(R^{L}\right)=U\left(R^{L}, T^{L}\left(R^{L}\right)\right)$. Students' expected payoff given the school's research strategy $R^{j}$ are $E\left[U\left(R^{j}, T^{\tau}\left(R^{j}\right)\right]-\Phi\left(R^{j}\right)=0\right.$.

The typical sequence of decisions goes like this (Figure 2 presents the decision tree):

- Step 0, Nature picks the type of school, either $L$ or $H$.

- Step 1, depending on their type, schools chose their research strategy.

- Step 2, students make their opinion about the type of school given the observed level of research and pay a tuition fee equal to their expected utility.

\footnotetext{
${ }^{6}$ It could be shown that all other strategies are dominated.
} 


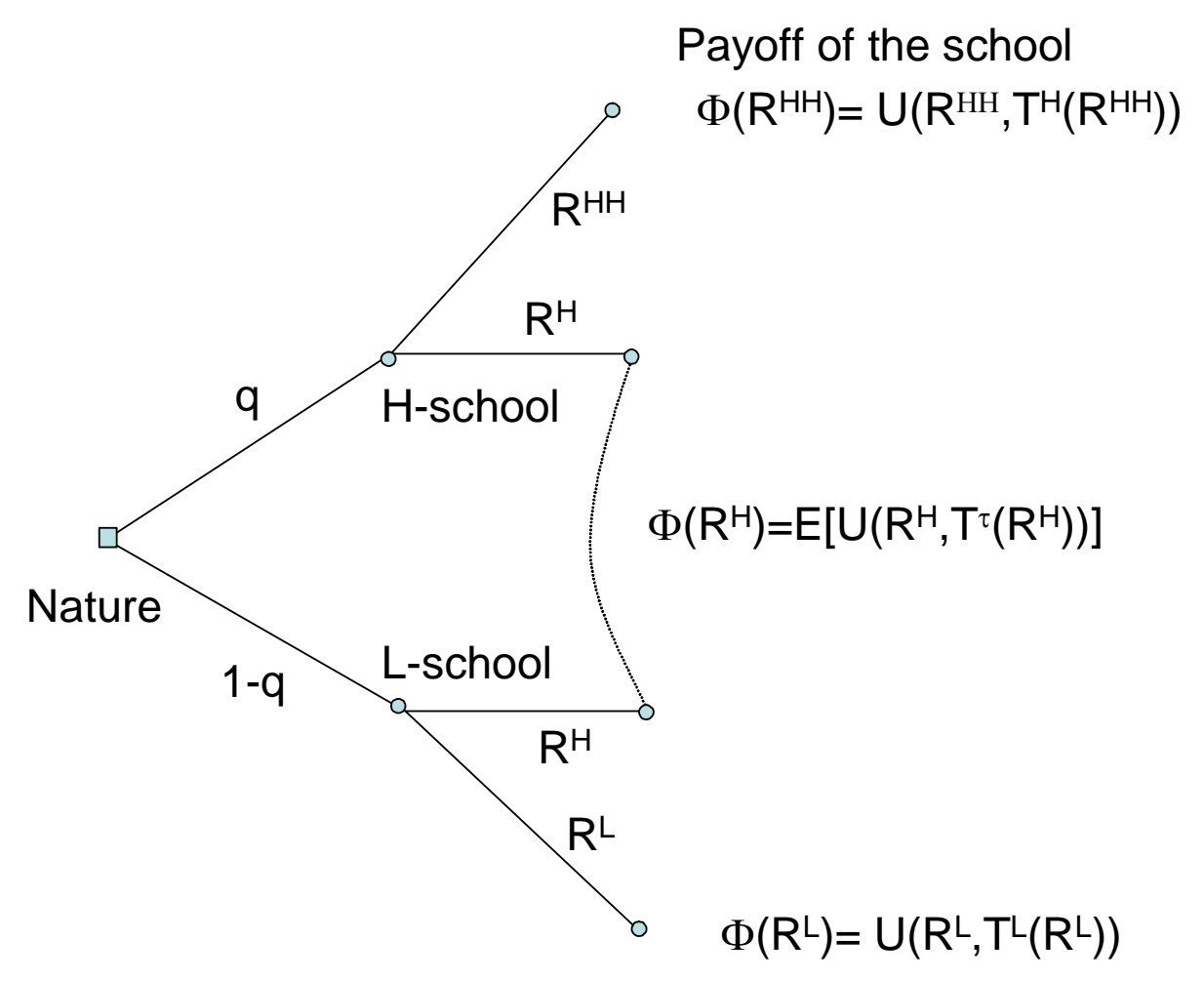

Figure 2: The Decision Tree

\section{Equilibria}

\subsection{Definition and types}

An equilibrium of this game is defined as a situation where schools research strategies are optimal (allow them to charge the largest fees) given students's beliefs about the type of school, and students' beliefs are correct given schools' optimal strategies. As is often the case with these games, we may distinguish between a separating equilibrium, where the strategy of the schools perfectly reveals their type, a pooling equilibrium where all schools implement the same strategy and thus no information about the type of school can be inferred from the observed research strategy, and hybrid equilibria wherein schools play Nash mixed strategies and their strategy carry some information about their type.

Before turning to analyzing the various equilibria, we would first notice that if the $L$-school cannot implement the perfect information optimal research level of the $H$-school, the prevailing equilibrium is of the separating type: each school is delivering its perfect information optimal 
amounts of research and education quality. In order to rule out this trivial case, in the following we assume that $L$-schools have the resources to deliver the amount of research $R^{H}$, or, in an equivalent way, that that $R^{H H}>R^{H}$ (see Appendix 1 - case 1 for the formal proof).

We also must call attention on a critical value of $a_{R}^{L}$, denoted by $\tilde{a}_{R}^{L}$ and implicitly defined by the equation $U\left(R^{H H}, T^{H}\left(R^{H H}\right)\right)=U\left(R^{L}, T^{L}\left(R^{L}\right)\right)$. In other words, there is a value of $a_{R}^{L}$ such that $H$-schools that implement the signaling strategy get the same payoff as $L$-schools that signals themselves by implementing the perfect information optimum of research (see Appendix 2 for the formal proof).

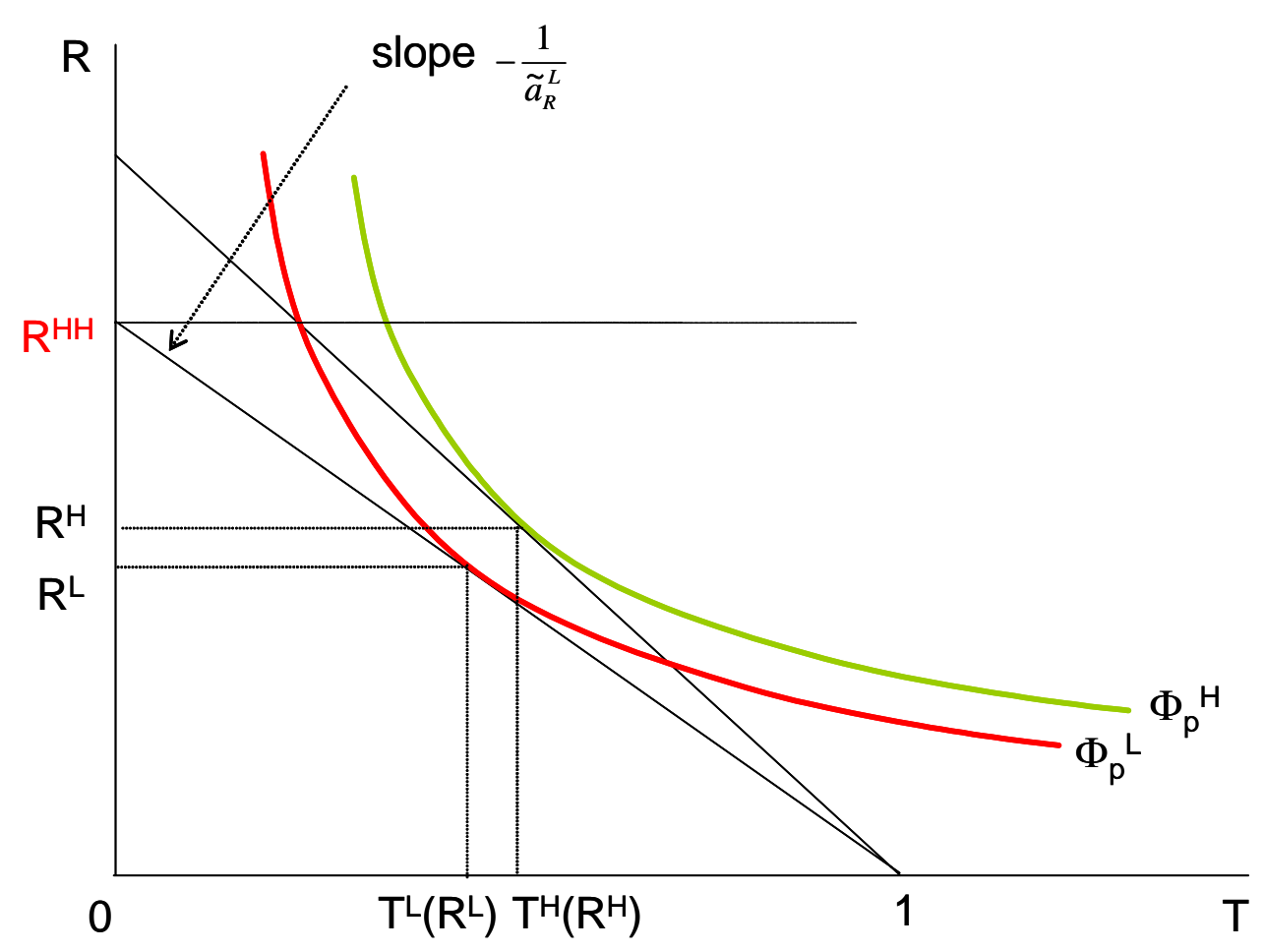

Figure 3: The Critical Threshold

Furthermore, for $a_{R}^{L}>\tilde{a}_{R}^{L}$, what we refer to as the "strong productivity gap" case, we have $U\left(R^{L}, T^{L}\left(R^{L}\right)\right)<U\left(R^{H H}, T^{H}\left(R^{H H}\right)\right)$, or:

$$
U\left(R^{H}, T^{L}\left(R^{H}\right)\right)<U\left(R^{L}, T^{L}\left(R^{L}\right)\right)<U\left(R^{H H}, T^{H}\left(R^{H H}\right)\right)<U\left(R^{H}, T^{H}\left(R^{H}\right)\right)
$$

In the opposite case, if the two type of scholars do not differ too much in their research productivity, 
that is if $\tilde{a}_{R}^{L}>a_{R}^{L}>a_{R}^{H}$, we check that $U\left(R^{L}, T^{L}\left(R^{L}\right)\right)>U\left(R^{H H}, T^{H}\left(R^{H H}\right)\right)$, or:

$$
U\left(R^{H H}, T^{H}\left(R^{H H}\right)\right)<U\left(R^{L}, T^{L}\left(R^{L}\right)\right)<U\left(R^{H}, T^{H}\left(R^{H}\right)\right)
$$

We recall that $U\left(R^{H}, T^{L}\left(R^{H}\right)\right)<U\left(R^{L}, T^{L}\left(R^{L}\right)\right)$.

We will show that depending on $a_{R}^{L}$ and $q$, the following equilibria can occur (Table 1):

\begin{tabular}{||l|l|l||}
\hline \hline EQUILIBRIA & \multicolumn{1}{|c||}{$\begin{array}{l}\text { Strong gap } \\
a_{R}^{L}>\tilde{a}_{R}^{L}\end{array}$} & $\begin{array}{c}\text { Moderate gap } \\
\tilde{a}_{R}^{L}>a_{R}^{L}>a_{R}^{H}\end{array}$ \\
\hline Pooling: All schools play $R^{H}, \forall \tau$ & $q \geq q_{1} \in[0,1]$ & $q \geq q_{2} \in[0,1]$ \\
\hline Signalling: All $H$ schools play $R^{H H}$ and all $L$ schools play $R^{L}$ & Always possible & Impossible \\
\hline Hybrid 1: All $L$ and some $H$ play $R^{H}$, the other $H$ play $R^{H H}$ & $q>q_{1} \in[0,1]$ & Impossible \\
\hline Hybrid 2: All $H$ and some $L$ play $R^{H}$, the other $L$ play $R^{L}$ & Impossible & $q<q_{2} \in[0,1]$ \\
\hline \hline
\end{tabular}

Table 1: Types of equilibria

We study first the strong productivity gap case, then turn to the moderate productivity gap case.

\subsection{The strong productivity gap case: $\tilde{a}_{R}^{L}<a_{R}^{L}$}

The strong productivity case corresponds to a situation where faculty research productivity in the $L$-schools is low enough, that is the time to produce one paper is larger than the critical value: $a_{R}^{L}>\tilde{a}_{R}^{L}$. We have shown that in this case the critical utilities can be ranked: $U\left(R^{H}, T^{L}\left(R^{H}\right)\right)<$ $U\left(R^{L}, T^{L}\left(R^{L}\right)\right)<U\left(R^{H H}, T^{H}\left(R^{H H}\right)\right)<U\left(R^{H}, T^{H}\left(R^{H}\right)\right)$.

\subsubsection{Pooling equilibrium: all schools do $R^{H}$}

We first can put forward the existence of a pooling equilibrium where all schools play $R^{H}$. The $L$-school does $R^{H}$ (it imitates the efficient production of research of a $H$-school) and the $H$-school decides not to signal itself by doing $R^{H H}$ (it chooses the amount $R^{H}$ ). Denoting a school's strategy as a function of its type by $s(\tau)$, in this equilibrium schools' optimal strategies are $s(\tau)=R^{H}$ $\forall \tau \in\{H, L\}$. 
Let us denote by $\operatorname{Pr}\left[\tau \mid R^{j}\right]$ the probability students assign to the event that a school is of type $\tau$ (with $\tau \in\{H, L\}$ ) if the research strategy is $R^{j}$, with $j \in\{H H, H, L\}$. Students' equilibrium beliefs can be written:

$$
\left\{\begin{array}{l}
\operatorname{Pr}\left[H \mid R^{H H}\right]=1 \\
\operatorname{Pr}\left[H \mid R^{H}\right]=q \\
\operatorname{Pr}\left[H \mid R^{L}\right]=0
\end{array}\right.
$$

with probabilities $\operatorname{Pr}\left[L \mid R^{j}\right]$ being complements to $\operatorname{Pr}\left[H \mid R^{j}\right]$.

Necessary conditions for this equilibrium are:

$$
\left\{\begin{array}{ll}
\Phi\left(R^{H H}\right)<\Phi\left(R^{H}\right) & \text { for the } H \text {-school } \\
\Phi\left(R^{L}\right)<\Phi\left(R^{H}\right) & \text { for the } L \text {-school }
\end{array} .\right.
$$

Since $\Phi\left(R^{L}\right)<\Phi\left(R^{H H}\right)$ because $U\left(R^{L}, T^{L}\left(R^{L}\right)\right)<U\left(R^{H H}, T^{H}\left(R^{H H}\right)\right)$, the equilibrium exists under the single condition $\Phi\left(R^{H H}\right)<\Phi\left(R^{H}\right)$. In turn, this implies that the frequency of $H$-schools is high enough:

$$
\begin{aligned}
\Phi\left(R^{H H}\right) & <\Phi\left(R^{H}\right) \\
\Leftrightarrow U\left(R^{H H}, T^{H}\left(R^{H H}\right)\right) & <E\left[U\left(R^{H}, T^{\tau}\left(R^{H}\right)\right)\right] \\
\Leftrightarrow U\left(R^{H H}, T^{H}\left(R^{H H}\right)\right) & <q U\left(R^{H}, T^{H}\left(R^{H}\right)\right)+(1-q) U\left(R^{H}, T^{L}\left(R^{H}\right)\right) \\
\Leftrightarrow q & >q_{1} \equiv \frac{U\left(R^{H H}, T^{H}\left(R^{H H}\right)\right)-U\left(R^{H}, T^{L}\left(R^{H}\right)\right)}{U\left(R^{H}, T^{H}\left(R^{H}\right)\right)-U\left(R^{H}, T^{L}\left(R^{H}\right)\right)} .
\end{aligned}
$$

Given that $U\left(R^{H}, T^{L}\left(R^{H}\right)\right)<U\left(R^{L}, T^{L}\left(R^{L}\right)\right)<U\left(R^{H H}, T^{H}\left(R^{H H}\right)\right)<U\left(R^{H}, T^{H}\left(R^{H}\right)\right)$, we know that $q_{1} \in[0.1]$. So this equilibrium exists if the frequency of $H$-schools is large enough. If there are not too many $L$-schools, they can fond into the mass of $H$-schools by implementing the same research strategy, to the expense of their teaching performance; furthermore $H$-schools have no incentive to signal themselves by increasing the amount of research, this strategy is too expensive.

This situation, which can hold in the short run, might not be stable in the long run. Since $H$ schools get the same tuition fees as $L$-schools, some of them may choose to become $L$-schools (they fire their productive researchers and hire less productive and probably less expensive ones). But 
in this case, the frequency of $H$-schools would fall below $q_{1}$, and this equilibrium would vanish. ${ }^{7}$

\subsubsection{Signalling equilibrium: $L$-schools do $R^{L}$ and $H$-schools do $R^{H H}$}

We can show that a separating equilibrium with signalling, where $H$-schools deliver the "signalling" level of research $R^{H H}$ and $L$-schools produce their efficient level, is always possible. In this equilibrium, schools' strategies are:

$$
\left\{\begin{array}{c}
s(H)=R^{H H} \\
s(L)=R^{L}
\end{array} .\right.
$$

Equilibrium beliefs:

$$
\left\{\begin{array}{c}
\operatorname{Pr}\left[H \mid R^{H H}\right]=1 \\
\operatorname{Pr}\left[H \mid R^{H}\right]=0 \\
\operatorname{Pr}\left[H \mid R^{L}\right]=0
\end{array} .\right.
$$

This equilibrium is feasible under the necessary conditions:

a) For the $L$-school, the condition $\Phi\left(R^{L}\right)>\Phi\left(R^{H}\right)$ is always true, given that $\Phi\left(R^{H}\right)=$ $\operatorname{Pr}\left[H \mid R^{H}\right] U\left(R^{H}, T^{H}\left(R^{H}\right)\right)+\operatorname{Pr}\left[L \mid R^{H}\right] U\left(R^{H}, T^{L}\left(R^{H}\right)\right)$ and $U\left(R^{L}, T^{L}\left(R^{L}\right)\right)>U\left(R^{H}, T^{L}\left(R^{H}\right)\right)$.

b) For the $H$-school, the condition $\Phi\left(R^{H H}\right)>\Phi\left(R^{H}\right)$ is equivalent to $U\left(R^{H H}, T^{H}\left(R^{H H}\right)\right)>$ $U\left(R^{H}, T^{L}\left(R^{H}\right)\right)$. Because in the case under scrutiny $U\left(R^{H}, T^{L}\left(R^{H}\right)\right)<U\left(R^{L}, T^{L}\left(R^{L}\right)\right)<U\left(R^{H H}, T^{H}\left(R^{H H}\right)\right)<$ $U\left(R^{H}, T^{H}\left(R^{H}\right)\right)$, this last condition is true.

In this case, the excessive research strategy implemented by the $H$-school implies that their education falls below their efficient education level, $T^{H}\left(R^{H H}\right)<T^{H}\left(R^{H}\right)$. Their education quality level may even be lower than the education level of $L$-schools.

This equilibrium, which holds in the short run, can be stable in the long run given that $H$ schools get larger tuition fees than $L$-schools. ${ }^{8}$

\subsubsection{Hybrid equilibrium 1: high excess research}

In this equilibrium, some $H$-schools decide to signal themselves by playing $R^{H H}$, and the other $H$-schools don't (they play $R^{H}$ ). In this case, $L$-schools may want to copy them and play $R^{H}$.

\footnotetext{
7 The prevailing equilibrium is analyzed in the next subsection.

8 To be more specific, if the cost of employing the highly productive researchers is $C H$ and the cost of employing the less productive researchers is $C L$, a H-school has no incentive to transform into a L-school if $\Phi\left(R^{H H}\right)-$ $\Phi\left(R^{L}\right)>(C H-C L)$.
} 
Denoting by $\sigma()$ a mixed strategy, schools' equilibrium strategies can be written as:

$$
\left\{\begin{array}{l}
\sigma(H)=\left\{\alpha R^{H H}+(1-\alpha) R^{H} \mid \alpha \in[0,1]\right\} \\
s(L)=R^{H}
\end{array} .\right.
$$

where $\alpha$ is the fraction of $H$-schools playing $R^{H H}$.

Using Bayes rule, and denoting by $\operatorname{Pr}\left[R^{j} \mid \tau\right]$ the probability that a school of type $\tau$ plays strategy $R^{j}$, equilibrium beliefs can be written:

$$
\left\{\begin{array}{l}
\operatorname{Pr}\left[H \mid R^{H H}\right]=1 \\
\operatorname{Pr}\left[H \mid R^{H}\right]=\frac{\operatorname{Pr}\left[R^{H} \mid H\right] \operatorname{Pr}[H]}{\operatorname{Pr}\left[R^{H}\right]}=\frac{(1-\alpha) q}{(1-\alpha) q+(1-q)} \\
\operatorname{Pr}\left[L \mid R^{L}\right]=1
\end{array} .\right.
$$

In equilibrium, a $H$-school must be indifferent between strategy $R^{H}$ and $R^{H H}$ :

$$
\begin{aligned}
\Phi\left(R^{H H}\right) & =\Phi\left(R^{H}\right) \\
& \Leftrightarrow U\left(R^{H H}, T^{H}\left(R^{H H}\right)\right)=\operatorname{Pr}\left[H \mid R^{H}\right] U\left(R^{H}, T^{H}\left(R^{H}\right)\right)+\operatorname{Pr}\left[L \mid R^{H}\right] U\left(R^{H}, T^{L}\left(R^{H}\right)\right) \\
& \Leftrightarrow U\left(R^{H H}, T^{H}\left(R^{H H}\right)\right)=\frac{(1-\alpha) q}{(1-\alpha) q+(1-q)} U\left(R^{H}, T^{H}\left(R^{H}\right)\right)+\frac{(1-q)}{(1-\alpha) q+(1-q)} U\left(R^{H}, T^{L}\left(R^{H}\right)\right) .
\end{aligned}
$$

The later equation allow us to determine $\alpha$ with respect to the predetermined variables:

$\alpha=\frac{q\left[U\left(R^{H}, T^{H}\left(R^{H}\right)\right)-U\left(R^{H H}, T^{H}\left(R^{H H}\right)\right)\right]-(1-q)\left[U\left(R^{H H}, T^{H}\left(R^{H H}\right)\right)-U\left(R^{H}, T^{L}\left(R^{H}\right)\right)\right]}{q\left(U\left(R^{H}, T^{H}\left(R^{H}\right)\right)-U\left(R^{H H}, T^{H}\left(R^{H H}\right)\right)\right.}$.

Obviously, $\alpha<1$. On the other hand, $\alpha>0$ if:

$$
q>q_{1} \equiv \frac{U\left(R^{H H}, T^{H}\left(R^{H H}\right)\right)-U\left(R^{H}, T^{L}\left(R^{H}\right)\right)}{U\left(R^{H}, T^{H}\left(R^{H}\right)\right)-U\left(R^{H}, T^{L}\left(R^{H}\right)\right)} .
$$

Recall that $q_{1}$ was previously defined as the threshold for which the pooling equilibrium can occur (Eq.6). Here $\alpha$ can be seen as a monotonously increasing function in $q$, with $\alpha=0$ for $q=q_{1}<1$ and $\alpha=1$ for $q=1$.

We can also check that the condition for a $L$-school always holds; indeed, $\Phi\left(R^{L}\right)<\Phi\left(R^{H}\right)=$ $\Phi\left(R^{H H}\right)$ given that $U\left(R^{L}, T^{L}\left(R^{L}\right)\right)<U\left(R^{H H}, T^{H}\left(R^{H H}\right)\right)$.

The frequency of $H$-schools who decide to signal by implementing the $R^{H H}$ strategy depends on the proportion $q$ of $H$-schools in total population of schools. The larger this proportion, less $H$ - 
schools would implement the oversignaling strategy. Clearly this equilibrium comes with some form of abnormal proliferation of research as compared to the perfect information case. All $L$-schools imitate the $H$ ones and adopt the research level $R^{H}$; as a reaction to this imitation strategy, some $H$-schools decide to signal their type by providing excessive research. In particular, for $q=q_{1}$, all $H$-schools do $R^{H H}$, and all $L$-schools do $R^{H}$, the overall volume of abnormal research is at its highest level.

In a long run setup, $H$-schools may want to become $L$-schools, since they could get the same fees at at lower cost. In this case, the frequency $q$ would decline over time; yet below $q_{1}$ this equilibrium vanishes too (as does the pooling one).

In the large productivity gap case, if $q<q_{1}$, only the signaling equilibrium exists. For $q>q_{1}$ the game presents multiple equilibria: the signaling, pooling and hybrid equilibrium here above are all feasible. Whatever the prevailing equilibrium, an abnormal level of research is delivered (as compared to the perfect information case), at the expense of quality in education. Yet, in a long run perspective, the frequency of $H$-schools would decline in both the pooling and the hybrid cases; when $q=q_{1}$ both these equilibria vanish to the benefit of the signaling equilibrium. ${ }^{9}$

We turn now to the analysis of the moderate productivity gap case.

\subsection{Moderate productivity gap: $\tilde{a}_{R}^{L}>a_{R}^{L}>a_{R}^{H}$}

When $\tilde{a}_{R}^{L}>a_{R}^{L}>a_{R}^{H}$, we have shown that $U\left(R^{H H}, T^{H}\left(R^{H H}\right)\right)<U\left(R^{L}, T^{L}\left(R^{L}\right)\right)<U\left(R^{H}, T^{H}\left(R^{H}\right)\right)$.

\subsubsection{Pooling equilibrium: all schools do $R^{H}$}

In this case too, an equilibrium where all schools play $R^{H}$ is feasible. $H$-schools does not signal themselves by doing $R^{H H}$, and the $L$-schools mimic the $H$-schools. Schools' strategies are $s(\tau)=$ $R^{H}, \forall \tau$.

We write the equilibrium beliefs:

$$
\left\{\begin{array}{c}
\operatorname{Pr}\left[H \mid R^{H H}\right]=1 \\
\operatorname{Pr}\left[H \mid R^{H}\right]=q \\
\operatorname{Pr}\left[H \mid R^{L}\right]=0
\end{array}\right.
$$

\footnotetext{
9 The Appendix 1 shows that the Hybrid Equilibrium 2 is impossible in the strong productivity gap case.
} 
Necessary existence conditions are:

a) For the $H$-school:

$\Phi\left(R^{H H}\right)=U\left(R^{H H}, T^{H}\left(R^{H H}\right)\right)<\operatorname{Pr}\left[H \mid R^{H}\right] U\left(R^{H}, T^{H}\left(R^{H}\right)\right)+\operatorname{Pr}\left[L \mid R^{H}\right] U\left(R^{H}, T^{L}\left(R^{H}\right)\right)=\Phi\left(R^{H}\right)$.

b) For the $L$-school:

$$
\Phi\left(R^{L}\right)=U\left(R^{L}, T^{L}\left(R^{L}\right)\right)<\operatorname{Pr}\left[H \mid R^{H}\right] U\left(R^{H}, T^{H}\left(R^{H}\right)\right)+\operatorname{Pr}\left[L \mid R^{H}\right] U\left(R^{H}, T^{L}\left(R^{H}\right)\right)=\Phi\left(R^{H}\right) .
$$

Given that $U\left(R^{H H}, T^{H}\left(R^{H H}\right)\right)<U\left(R^{L}, T^{L}\left(R^{L}\right)\right)$, a sufficient condition is:

$$
U\left(R^{L}, T^{L}\left(R^{L}\right)\right)<q U\left(R^{H}, T^{H}\left(R^{H}\right)\right)+(1-q) U\left(R^{H}, T^{L}\left(R^{H}\right)\right)
$$

equivalent to:

$$
q>q_{2} \equiv \frac{U\left(R^{L}, T^{L}\left(R^{L}\right)\right)-U\left(R^{H}, T^{L}\left(R^{H}\right)\right)}{U\left(R^{H}, T^{H}\left(R^{H}\right)\right)-U\left(R^{H}, T^{L}\left(R^{H}\right)\right)}
$$

Because $U\left(R^{H}, T^{L}\left(R^{H}\right)\right)<U\left(R^{L}, T^{L}\left(R^{L}\right)\right)<U\left(R^{H}, T^{H}\left(R^{H}\right)\right)$, we have $q_{2} \in[0,1]$.

So this equilibrium where the research level is substantial, given that $L$-schools do as much research as $H$-schools in perfect information, can occur for $q>q_{2}$. Because all $L$-schools do more research than their efficient level, the quality of their teaching is hampered.

In this case too, if schools can change their faculty profile in the long run, some $H$-schools may want to turn into $L$-schools. But in this case, the proportion of $H$-schools will decline. We study in the next section what can happen if this proportion falls below $q_{2}$.

\subsubsection{Hybrid equilibrium 2: Low excess research}

In this equilibrium, $H$-schools play $R^{H}$ and a only a fraction $\beta$ of the $L$-schools do the same.

$$
\left\{\begin{array}{l}
s(H)=R^{H} \\
\sigma(L)=\left\{\beta R^{H}+(1-\beta) R^{L} \mid \beta \in[0,1]\right\}
\end{array}\right.
$$

Equilibrium beliefs are:

$$
\left\{\begin{array}{l}
\operatorname{Pr}\left[H \mid R^{H}\right]=\frac{\operatorname{Pr}\left[R^{H} \mid H\right] \operatorname{Pr}[H]}{\operatorname{Pr}\left[R^{H}\right]}=\frac{q}{q+(1-q) \beta} \\
\operatorname{Pr}\left[L \mid R^{L}\right]=1
\end{array} .\right.
$$


In equilibrium an $L$-school must be indifferent between playing $R^{L}$ or $R^{H}$, that is $\Phi\left(R^{L}\right)=\Phi\left(R^{H}\right)$. This condition leads to the equilibrium frequency of $L$-schools doing $R^{H}$.

$$
\begin{aligned}
U\left(R^{L}, T^{L}\left(R^{L}\right)\right) & =\operatorname{Pr}\left[H \mid R^{H}\right] U\left(R^{H}, T^{H}\left(R^{H}\right)\right)+\operatorname{Pr}\left[L \mid R^{H}\right] U\left(R^{H}, T^{L}\left(R^{H}\right)\right) \\
& =\frac{q U\left(R^{H}, T^{H}\left(R^{H}\right)\right)+\beta(1-q) U\left(R^{H}, T^{L}\left(R^{H}\right)\right)}{q+(1-q) \beta} \\
\Leftrightarrow \beta & =\frac{q}{(1-q)} \frac{\left[U\left(R^{H}, T^{H}\left(R^{H}\right)\right)-U\left(R^{L}, T^{L}\left(R^{L}\right)\right)\right]}{\left[U\left(R^{L}, T^{L}\left(R^{L}\right)\right)-U\left(R^{H}, T^{L}\left(R^{H}\right)\right)\right]} .
\end{aligned}
$$

We remark that $\beta$ is an increasing function in $q$. For $q=0$ we have $\beta=0$ and for $q=q_{2}$, such as defined in Equation (18), we get $\beta=1$. So this equilibrium prevails whenever $q<q_{2}$. Some $L$-schools do too much research; their frequency increases if the proportion of $H$-schools goes up.

We can also check that for a $H$-school, the condition $\Phi\left(R^{H H}\right)<\Phi\left(R^{H}\right)=\Phi\left(R^{L}\right)$ always holds given that $U\left(R^{H H}, T^{H}\left(R^{H H}\right)\right)<U\left(R^{L}, T^{L}\left(R^{L}\right)\right)$.

Since $L$-schools that get the same fees as $H$-schools but have lower costs, in the long run the $H$-schools might want to transform themselves into $L$-schools: $q$ would decline, and so will do $\beta$. At the end of the day all schools would become of the $L$-type along a standard adverse selection process. ${ }^{10} \quad$ Although losses connected to imperfect information would disappear, the overall production of research is the lowest that such an economy can deliver.

\section{Conclusion}

There is a lot of criticism these days about B-Schools doing too much and not always relevant research. Furthermore, critics point out that the excessive emphasis on research comes at the expense of teaching quality. This paper shows in a simple signaling framework the conditions in which such scenarios are possible. In particular, we argue that if there is a large research productivity gap between top and normal schools, the latter would implement the same level of research as the top-tier schools only in order to manipulate student's expectations. The rational response of leading schools is to implement excessive research strategies only to signal themselves to future students. As an upshot of these, as long as information is imperfect, there is little chance to obtain an efficient separation between the two types of schools. Policies might consider make

\footnotetext{
10 The Appendix1 shows that the two other equilibria put forward in the large productivity gap case are impossible in the moderate research gap case.
} 
it hard for $L$-schools to implement the level of research of the $H$-schools. Yet such measure might not benefit of political support since it conflicts with the principle of managerial autonomy of these institutions.

Even if the signaling equilibrium is socially inefficient, it is probably less detrimental than a situation where all top schools choose to become normal schools by giving up the research oriented recruitment of faculty, what can be expected in low productivity gap case. To avoid this poor outcome, public policy should make sure that the productivity gap between a small group of top tier schools and the rest of them is large enough. In this case the signaling equilibrium will prevail. If the frequency of leading schools is too big, the analysis has shown that other equilibria can occur, wherein leading schools have no incentive to invest in research. These recommendations are consistent with the EU research and superior education policy of supporting the creation of pan-European centres of excellence "competitive at a global scale" (EU, 2007).

\section{References}

Armstrong, J. S., 1995. The devil's advocate responds to an MBA student's claim that research harms learning, Journal of Marketing, 59, pp. 101-106.

AACSB, 2007. Impact of Research, Draft, AACSB. Online: www.aacsb.edu /resource_centers /research/Impact_of_Research_Report-DRAFT.pdf.

Bennis, Warren G. and James O'Toole, 2005. How Business schools lost their way, Harvard Business Review, May 2005, pp. 96-104.

Becker, Elisabeth, Cotton M. Lindsat and Gary Grizzle, 2003. The derived demand for faculty research, Managerial and Decision Economics, 24, 8, pp. 549-567.

Besancenot, Damien and Radu Vranceanu, 2007, Can incentives for research harm research? A business schools' tale, Journal of Socio Economics, Forthcoming, Online www.elsevier.org.

Besancenot, Damien, Kim Huynh, Radu Vranceanu, 2008. The read or write dilema in academic production: A transatlantic perspective, American Economist, Forthcoming.

Demski, Joel and Jerold L. Zimmerman, 2000. On "research vs. teaching": A long term perspective, Accounting Horizons, 14, 3, pp. 343-352.

Coupé, Tom, What do we know about ourselves? On the economics of economics, Kyklos, 57, 2, pp 197-216.

EU 2007. The European research area: New perspectives, European Commission, Green Paper, $\operatorname{COM}(2007)$ 116. Online: http://ec.europa.eu/ research/ era/pdf/ eragreenpaper_en.pdf.

Faria, J. Ricardo, 2001, Rent seeking in academia: the consultancy disease, American Economist, 45 , pp. 69-74 
Kwok, Chuck C. Y. and Jefferey S. Arpan, 2002. Internationalizing the business school: A global survey in 2000, Journal of International Business Studies, 33,3, pp. 571-581.

Paul, Chris W. and Paul C. Rubin, 1984. Teaching and research: the human capital paradigm, Journal of Economic Education, Spring, pp. 142-147.

Pfeffern, Jeffery and Christina T. Fong, 2002, The end of business schools? Less succes than meets the eye, Academy of Management Learning and Education, 2002, 1, 1, 78-95.

Spence, Michael, 1973. Job market signaling, Quarterly Journal of Economics, 87, 3, pp. $355-374$.

Spence, Michael, 2002. Signaling in retrospect and the informational structure of markets, Nobel Prize Lecture, American Economic Review, 92, 3, pp. 434-459.

Vickers, John, 1986. Signaling in a model of monetary policy with incomplete information, Oxford Economic Papers, 38, 3, pp. 443-455.

\section{Appendix 1. Trivial and impossible equilibria}

Case 1 Trivial separating equilibrium: each school delivers the perfect information (or efficient) amount of research.

In a separating equilibrium, schools' strategies are $s(\tau)=R^{\tau}$ with $\tau \in\{H, L\}$. The probability that the school is of type $\tau$ if the research strategy is $R^{j}$ was denoted by $\operatorname{Pr}\left[\tau \mid R^{j}\right]$. The equilibrium beliefs are: $\operatorname{Pr}\left[H \mid R^{H}\right]=1$ and $\operatorname{Pr}\left[L \mid R^{L}\right]=1$. In this equilibrium, research strategies reveal the type of the school. Students make no assessment error, tuition fees are $\Phi\left(R^{H}\right)=U\left(R^{H}, T^{H}\left(R^{H}\right)\right)$ and $\Phi\left(R^{L}\right)=U\left(R^{L}, T^{L}\left(R^{L}\right)\right)$. A necessary condition of existence for this equilibrium is that a type $L$-school prefers $\Phi\left(R^{L}\right)$ to $\Phi\left(R^{H}\right)$. Given that $U\left(R^{L}, T^{L}\left(R^{L}\right)\right)<U\left(R^{H}, T^{H}\left(R^{H}\right)\right)$, a $L$-school always find more profitable to play $R^{H}$ than $R^{L}$,i.e. $\Phi\left(R^{L}\right)<\Phi\left(R^{H}\right)$. Hence this equilibrium can appear only if the strategy $R^{H}$ is not possible for the $L$-school, because its resources are too small, i.e. if $R^{H H} \leq R^{H}$.

Case 2 In the "high research gap" case, the Hybrid equilibrium 2 is impossible.

We recall that $U\left(R^{H}, T^{L}\left(R^{H}\right)\right)<U\left(R^{L}, T^{L}\left(R^{L}\right)\right)<U\left(R^{H H}, T^{H}\left(R^{H H}\right)\right)<U\left(R^{H}, T^{H}\left(R^{H}\right)\right)$. Schools' strategies can be written $s(H)=R^{H}$ and $\sigma(L)=\left\{\beta R^{H}+(1-\beta) R^{L} \mid \beta \in[0,1]\right\}$. The equilibrium beliefs are $\operatorname{Pr}\left[H \mid R^{H}\right]=\frac{\operatorname{Pr}\left[R^{H} \mid H\right] \operatorname{Pr}[H]}{\operatorname{Pr}\left[R^{H}\right]}=\frac{q}{q+(1-q) \beta}$ and $\operatorname{Pr}\left[L \mid R^{L}\right]=1$. Necessary and sufficient conditions are $\Phi\left(R^{L}\right)=\Phi\left(R^{H}\right)$. For a $L$-school and $\Phi\left(R^{H H}\right)<\Phi\left(R^{H}\right)$ for a $H$-school. But $\Phi\left(R^{H H}\right)<\Phi\left(R^{H}\right)=\Phi\left(R^{L}\right)$ is tantamount to $U\left(R^{H H}, T^{H}\left(R^{H H}\right)\right)<U\left(R^{L}, T^{L}\left(R^{L}\right)\right)$ which is false in our case. 
Case 3 In the "moderate research gap" case, the signalling equilibrium where the L-school does $R^{L}$ and the $H$-school does $R^{H H}$ is impossible.

Recall that in this case $U\left(R^{H H}, T^{H}\left(R^{H H}\right)\right)<U\left(R^{L}, T^{L}\left(R^{L}\right)\right)<U\left(R^{H}, T^{H}\left(R^{H}\right)\right)$.

Schools' strategies are: $s(H)=R^{H H}$ and $s(L)=R^{L}$. Equilibrium beliefs $\operatorname{Pr}\left[H \mid R^{H H}\right]=1$ and $\operatorname{Pr}\left[H \mid R^{H}\right]=\operatorname{Pr}\left[H \mid R^{L}\right]=0$. This equilibrium is feasible if $\Phi\left(R^{H H}\right)>\Phi\left(R^{H}\right)$. But this condition implies $U\left(R^{H H}, T^{H}\left(R^{H H}\right)\right)>U\left(R^{H}, T^{L}\left(R^{H}\right)\right)$. In the case of a moderate gap this inequality is false.

Case 4 In the "moderate research gap" case, the Hybrid equilibrium 1 (partial over signaling by $H$-schools; high excess research equilibrium) is impossible

This case implies $U\left(R^{H H}, T^{H}\left(R^{H H}\right)\right)<U\left(R^{L}, T^{L}\left(R^{L}\right)\right)<U\left(R^{H}, T^{H}\left(R^{H}\right)\right)$.

Strategies are $\sigma(H)=\left\{\alpha R^{H H}+(1-\alpha) R^{H} \mid \alpha \in[0,1]\right\}$ and $s(L)=R^{H}$. Beliefs can be written: $\operatorname{Pr}\left[H \mid R^{H H}\right]=1, \operatorname{Pr}\left[H \mid R^{H}\right]=\frac{\operatorname{Pr}\left[R^{H} \mid H\right] \operatorname{Pr}[H]}{\operatorname{Pr}\left[R^{H}\right]}=\frac{(1-\alpha) q}{(1-\alpha) q+(1-q)}$ and $\operatorname{Pr}\left[H \mid R^{L}\right]=0$. The necessary and sufficient condition for a $L$-school : $\Phi\left(R^{L}\right)<\Phi\left(R^{H}\right)=\Phi\left(R^{H H}\right)$ or $U\left(R^{L}, T^{L}\left(R^{L}\right)\right)<$ $U\left(R^{H H}, T^{H}\left(R^{H H}\right)\right)$, which is false.

\section{Appendix 2. Existence of $\tilde{a}_{R}^{L}$}

In order to verify that a value such as $\tilde{a}_{R}^{L}$ does exist, we must study how $U\left(R^{H H}, T^{H}\left(R^{H H}\right)\right)$ and $U\left(R^{L}, T^{L}\left(R^{L}\right)\right)$ vary with respect to $a_{R}^{L}$. On the one hand, it can be shown that the efficient utility level $\Phi\left(R^{H H}\right)=U\left(R^{H H}, T^{H}\left(R^{H H}\right)\right)$ is an increasing function in $a_{R}^{L}: d \Phi\left(R^{H H}\right) / d a_{R}^{L}>0$.

The proof begins with the remark that $\Phi\left(R^{H H}\right)$ is a decreasing function of $R^{H H}$ for any $R^{H H}$ in the interval $\left[R^{H}, 1 / a_{R}^{H}\right]$. Indeed, $d \Phi\left(R^{H H}\right)=U_{R}^{\prime} d R^{H H}+U_{T}^{\prime}\left(\frac{d T^{H}\left(R^{H H}\right)}{d R^{H H}}\right) d R^{H H}$ where $T^{H}\left(R^{H H}\right)=1-a_{R}^{H} R^{H H}$. It turns out that $d \Phi\left(R^{H H}\right)=\left(U_{R}^{\prime}-a_{R}^{H} U_{T}^{\prime}\right) d R^{H H}$. But $R^{H H}=\frac{1}{a_{R}^{L}}$ so $d R^{H H}=-\frac{1}{\left(a_{R}^{L}\right)^{2}} d a_{R}^{L}$. Thus: $d \Phi\left(R^{H H}\right)=-\frac{1}{\left(a_{R}^{L}\right)^{2}}\left(U_{R}^{\prime}-a_{R}^{H} U_{T}^{\prime}\right) d a_{R}^{L}$ or, in an equivalent way, $\frac{d \Phi\left(R^{H H}\right)}{d a_{R}^{L}}=-\frac{a_{R}^{H} U_{R}^{\prime}}{\left(a_{R}^{L}\right)^{2}}\left(\frac{1}{a_{R}^{H}}-\frac{U_{T}^{\prime}}{U_{R}^{\prime}}\right)$. Given that $-\frac{U_{T}^{\prime}}{U_{R}^{\prime}}=\left(\frac{d R}{d T}\right)_{U=C t}$ and because $\frac{1}{a_{R}^{H}}-\frac{U_{T}^{\prime}}{U_{R}^{\prime}}<0$ for $R^{H H}>R^{H}$, we get $\frac{d \Phi\left(R^{H H}\right)}{d a_{R}^{L}}>0$.

On the other hand, the efficient utility level $\Phi\left(R^{L}\right)=U\left(R^{L}, T^{L}\left(R^{L}\right)\right)$ is a decreasing function of $a_{R}^{L}: d \Phi\left(R^{L}\right) / d a_{R}^{L}<0$.

In the limit case $a_{R}^{L}=a_{R}^{H}$, we check $\Phi\left(R^{L}\right)=U\left(R^{H}, T^{H}\left(R^{H}\right)\right)>U\left(R^{H H}, T^{H}\left(R^{H H}\right)\right)=$ 
$\Phi\left(R^{H H}\right)$ and, in the opposite case, $a_{R}^{L}=1 / R^{H}$ (i.e.: $R^{H}=R^{H H}$ ) we verify $\Phi\left(R^{L}\right)<\Phi\left(R^{H H}\right)=$ $U\left(R^{H}, T^{H}\left(R^{H}\right)\right)$. So there is a $\tilde{a}_{R}^{L}$ in the interval $\left[a_{R}^{H}, 1 / R^{H}\right]$ for which $\Phi\left(R^{L}\right)=\Phi\left(R^{H H}\right)$. 